\title{
Modos de apropiación territorial en Belice: una genealogía institucional de la propiedad
}

Territorial Appropriation in Belize: An Institutional Genealogy of Property

Modos de apropriação territorial no Belize: uma genealogia institucional da propriedade

Odile Hoffmann ${ }^{*}$

Recibido: 7 de marzo de 2019

Aprobado: 11 de octubre de 2019

Doi: https://www.doi.org/10.12804/revistas.urosario.edu.co/territorios/a.7738

Para citar este artículo:

Hoffmann, O. (2020). Modos de apropiación territorial en Belice: una genealogía institucional de la propiedad. Territorios, (42-Especial), 1-18. https://www.doi.org/10.12804/revistas.urosario.edu.co/territorios/a.7738

* IRD-CIESAS; LMI MESO (Francia, México). Correo electrónico: odile.hoffmann@ird. fr. ORCID: https://orcid. org/0000-0001-9813-0134 
Palabras clave

Propiedad, derechos sobre la tierra, régimen colonial.

Keywords

Property, land rights, colonial regime, juridical-territorial knowledge.

Palavras-chave

Propriedade, direitos sobre a terra, regime colonial.

\section{territorias 42-Especial}

RESUMEN

En Belice, la propiedad de la tierra se instituye en contextos coloniales marcados por una gran precariedad jurídica que desemboca en una gran complejidad político-territorial. El proceso de institución de la propiedad se da en varias fases que corresponden a etapas de la construcción colonial, cada una de las cuales genera distintos modelos de negociación e interacción entre comunidades políticas en torno a la propiedad de la tierra. Mediante revisión documental y entrevistas, se ve cómo las nociones y categorías jurídicas se suceden unas a las otras sin llegar a sustituirse, pero generan configuraciones entrelazadas, empalmes y superposiciones que desembocan en situaciones de extrema confusión. Para entender las confusiones y sus trasfondos políticos, el artículo propone como método seguir la evolución del saber territorial jurídico a través una genealogía institucional de la propiedad en cuatro etapas, a lo largo de los siglos XIX-XX.

\section{ABSTRACT}

In Belize, land property rights have been instituted in colonial contexts marked by great precariousness, and juridical and political complexity. The process of the institution of land property registry took place in several phases that correspond to stages of colonial construction, each one generating different types of negotiation and interaction between political communities. The notions and legal categories elaborated around land property followed one another without replacing each other, and they reached interlaced configurations, splices, and overlays that lead to situations of extreme confusion. To understand the confusion and its political backgrounds, we propose a methodology that follows the legal territorial knowledge's evolution through an institutional genealogy of property in four stages, over the nineteenth and the twentieth centuries.

\section{RESUMO}

No Belize a propriedade da terra se institui em contextos coloniais marcados por uma grande precariedade jurídica que resulta, finalmente, em uma forte complexidade político-territorial. O processo de instituição da propriedade dá-se em várias fases que correspondem a etapas da construção colonial, cada uma gerando diferentes modelos de negociação e interação entre comunidades políticas em torno à propriedade da terra. Através de revisão documental e entrevistas, é possível ver como as noções e categorias jurídicas se sucedem umas às outras sem conseguir substituir-se, chegando a configurações de entrelaçamento, junções, e sobreposições que resultam em situações de extrema confusão. Para entender as confusões e seus contextos políticos, o artigo propõe, como método, seguir a evolução do saber territorial jurídico através de uma genealogia institucional da propriedade em quatro etapas, ao longo de dois séculos (XIX-XX). 
En contextos coloniales, la dominación territorial, la que se ejerce sobre y mediante el espacio, no solo enfrenta a dominados y dominantes, también confronta registros de saberes y distintos modelos cognitivos que posibilitan o rechazan proyectos de ocupación y explotación del espacio. Es lo que genéricamente llamaremos "saber territorial": los conocimientos elaborados en torno al espacio. Para entenderlos, contemplamos las tres formas básicas de aprehender el espacio tal y como lo propuso Buttimer hace ya medio siglo (1969): ${ }^{1}$ el espacio existe como representación (por ejemplo, los mapas), como práctica (el espacio vivido, explotado) y como objeto (susceptible de apropiación).

En la primera acepción, el saber-conocer del espacio pasa, en contexto colonial, por unas acciones elementales como nombrar, medir, delimitar y cartografiar el espacio nuevamente colonizado. Esta se conformó durante siglos como un campo de conocimientos reservado al sector dominante, que podía controlar la técnica y tenía la capacidad de imponer, a través de la representación autorizada, sus concepciones del espacio. Otra forma de construir saber territorial atañe al espacio vivido, practicado, explotado. Este saberexplotar el espacio y sus recursos (mineros, agrícolas, forestales, etc.) suele basarse en un conocimiento tradicional, venido de generaciones atrás ("conocimiento tradicional” o vernacular) o, al contrario, en experiencias importadas de lugares lejanos. Según los espacios y recursos, esta distinción tiende a borrarse a favor de competencias mestizas o a exacerbarse en el caso de sistemas de explotación radicalmente distintos (minas, monocultivos).

Un tercer tipo de saber territorial, que es el que nos interesa en este trabajo, ${ }^{2}$ considera el espacio como un objeto susceptible de apropiación jurídica, sea para excluir a los demás o para regular su acceso a ciertas porciones de tierra. La propiedad, figura central de la apropiación jurídica, es definida como la reivindicación legítima a poseer un objeto, en este caso: la tierra. La legitimación suele venir de instancias del Estado, pero se extiende a otros ámbitos de legitimación, particularmente en contextos en los que el Estado es precario y hasta ausente, como fue el caso en Belice durante décadas.

La propiedad es una relación social en torno a un objeto (la tierra), que como cualquier relación social no existe naturalmente ni es unívoca, sino que se construye por medio de negociaciones entre actores políticos e instrumentos especializados (leyes y reglamentos, registros administrativos, etc.), insertos en las relaciones de poder imperantes en un lugar y un tiempo dado. Es un recurso técnico y político para controlar el espacio, manejar la gente que ahí vive o que de ahí se enriquece, y eventualmente para construir territorio económico, cultural y político. El análisis del saber territorial que proponemos, enfocado hacia la construcción
${ }^{1}$ Geógrafa precursora a la que siguieron -con matices y varios términos pero con la misma idea de un espacio constituido por una triada de funciones o significados - Frémont (1976) y Lefebvre (1974), entre otros.

${ }^{2}$ En otros trabajos be analizado la construcción del saber cartográfico en Belice (Hoffmann, 2014) yel uso politico del saber espacial (Hoffmann, 2018).

\section{territarias 42-Especial}

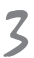




\section{tersitorias} 42-Especial de la propiedad, se centra en los vínculos entre esta y la ciudadanía (Lund, 2013; Sikor \& Lund, 2009; Hoffmann, 2018).

El análisis del proceso de institución de la propiedad en Belice durante los siglos XVII-XIX posibilita entender los vínculos entre los saberes territoriales y los contextos socioeconómicos y políticos que organizan la vida colectiva en un momento dado. La propiedad de la tierra fue instituida en varias fases a medida que la sociedad local y el territorio se consolidaban como colonia británica. La construcción jurídica de la propiedad, lejos de ser un proceso lineal, se dio en medio de confusiones y contradicciones que, si no las provocaron, contribuyeron a las desigualdades y exclusiones contemporáneas.

El análisis lleva a reconocer varias fases de institucionalización de la propiedad que corresponden a etapas de la construcción colonial, que generaron distintos modelos de negociación e interacción entre comunidades políticas en torno a la propiedad de la tierra. Las elaboraciones de nociones y categorías jurídicas se suceden unas a otras sin llegar a sustituirse, pero generan configuraciones entrelazadas, empalmes y superposiciones que desembocan muchas veces en situaciones de extrema confusión. Para entender la génesis de estas confusiones y sus trasfondos políticos, proponemos seguir la evolución del saber territorial jurídico a través de una genealogía institucional de la propiedad en cuatro etapas:
- La posesión en tiempos del asentamiento (Settlement de los Baymen, siglo XVIII)

- La intervención británica y la primera institucionalización (1817)

- La administración del territorio y la normalización colonial (1861)

- La modernización en los años de gobierno autónomo (1962)

\section{La posesión en tiempos del asentamiento (Settlement de los Baymen)}

Cuando llegaron los europeos a las costas de la bahía de Honduras en el siglo XVII, buscaban un lugar de protección para desempeñar actividades poco o no controladas por las autoridades coloniales, fueran ilícitas o no. De ahí nace uno de los relatos fundadores de Belice como tierra de contrabando y piratas. Belice es un emplazamiento valorado por estar en los confines del imperio, lejos de los centros continentales (México, Guatemala) y fuera de las circulaciones caribeñas. Es decir, por ser un lugar/espacio fuera de los ámbitos del poder instituido. Los colonos empujaron hacia el interior a las poblaciones residentes que, sin embargo, resistieron la invasión con manifestaciones colectivas armadas hasta finales del siglo XIX (Bolland, 2004).

Después de la era de la piratería (que culmina a principios del siglo XVIII), la vida de los colonos se organiza en torno a la extracción de recursos forestales 
(principalmente palo de tinte, pero también chicle y luego caoba), que tienen un alto valor en el mercado. Belice se inserta en los circuitos internacionales dominados por Campeche y los ingleses. A partir de 1724, los colonos importan esclavos que muy pronto son más numerosos que ellos y que los demás grupos de población (maya principalmente). Si el número de habitantes blancos queda relativamente estable y siempre bajo (menos de 300 hombres), durante el siglo siguiente, a partir de 1780, el número de esclavos ronda alrededor de los 2000 , mientras la población de "negros libres" y "personas de color" aumenta de 380 en 1790 a más de 2000 en 1830 (Dobson, 1973, p. 338; Leslie, 2004).

El tratado de París en 1763, y luego el de Versalles ${ }^{3}$ en 1783, confirman el derecho de los colonos, en su mayoría británicos, a ocupar ciertas porciones de la bahía de Honduras (llamada desde entonces British Honduras), pero mantiene una gran ambivalencia: los settlers solo tienen el derecho de explotar el palo de campeche (o palo de tinte) sobre un territorio específico - entre los ríos Hondo y Belice-; tienen prohibida cualquier otra actividad como la agricultura o la fundación de pueblos. Se autoriza la presencia de sujetos británicos, pero se reafirma la soberanía de España sobre dichas tierras. El convenio de Londres en 1786 ratifica estas disposiciones a la vez que amplía el área concedida hacia el sur, hacia el río Sibun (Toussaint, 1993). Estas iniciativas diplomáticas siembran las bases de una regulación de la propiedad entre potencias coloniales, ignorando totalmente los derechos de las poblaciones nativas, en este caso la maya.

Desde sus inicios, la Honduras británica es, para los colonos europeos, un territorio de explotación extractiva más que de colonización. El valor de la tierra se refiere a la presencia de madera; por lo tanto, desaparece con el agotamiento del recurso forestal. Los primeros settlers europeos, poco numerosos como vimos, se reparten los recursos (las áreas con palos de tinte) entre sí, entre hombres, específicamente entre hombres blancos. La vida colectiva se organiza en ausencia de cualquier institucionalidad, con la intervención esporádica de la autoridad británica desde Jamaica. En 1765 se elabora un código rudimentario (el Burnaby Code, de 12 artículos) para regular la vida en común, sancionar los delitos e instituir reuniones periódicas, los public meetings, para tratar y adoptar las disposiciones que atañen los asuntos públicos.

En uno de estos public meetings se dictan las primeras Locations Laws (1787). Estas no son realmente leyes, sino medidas que apuntan a regular el derecho de posesión sobre las parcelas de explotación forestal llamadas locations. Un comentario de 1802 describe la modalidad de apropiación así:

El modo de tomar posesión de un terreno es el siguiente: el individuo ubica un lugar
${ }^{3}$ El Tratado de Versalles de 1783 es firmado por Francia, España y Gran Bretaña, que estatuye la atribución, entre dichas naciones, de los territorios situados en América y el Caribe, en Europa (Gibraltar, Dunkerque), en Africa (Gorée) y en India (las dependencias francesas). Entre otros aspectos, España exige el retiro de los británicos de todas las costas de América central y del sur, entre ellas la Mosquitia. A pesar de la fuerte resistencia de parte de los colonos radicados en las costas centroamericanas, la Convención de Londres, firmada ente el reino de Gran Bretaña y el imperio español tres años más tarde, en 1786, impone la evacuación de la Mosquitia, cuyos residentes británicos (blancos y negros; amos, libres y esclavos) se refugian en Belice. Como contra parte, España mantiene el derecho de los británicos para explotar la madera en la Bahía de Honduras.

\section{territarios 42-Especial}




\section{tersitorias} 42-Especial desocupado, sobre el cual erige una choza y una piedra de moler, esto se considera como una marca de posesión y una vez se ha registrado con el secretario de la Corte de Magistrados, tiene derecho a ocupar un espacio de nueve millas a lo largo del río a las orillas del cual ha erigido esta cabaña y piedra de moler (Antochiw \& Breton, 1992, p. 92).

$\mathrm{Al}$ analizar este sistema un siglo después, los autores de un informe británico lo califican de "primitivo" pero a la vez de "bastante original", combina varias normas y regulaciones y es adaptado a las necesidades de los colonos (Bristowe \& Wright, 1888-89, p. 79).

Con estas Locations Laws se establece un sistema flexible, adaptado al contexto de colonización incipiente, de incertidumbre legal, de poca población y de una explotación forestal itinerante, que sigue los descubrimientos y agotamientos de los recursos. Se reparten los derechos de propiedad (formalmente: derechos de posesión) con referencia a la capacidad de explotar la madera y la anterioridad de explotación, más que por títulos (escasos) o cercados de las porciones (proceso imposible de llevar a cabo en estos ambientes forestales despoblados).

Esta apropiación elemental se ve reflejada en los mapas de la época, donde aparecen los nombres de los posesionarios aproximadamente situados en sus locations. Al final del siglo XVIII,
La propiedad de esos lotes era ya limitada a un pequeño número de apellidos, algunos de los cuales aparecen muchas veces Potts, Hoare, Bartlett, McCauley, O’Brien y Tucker. Este puñado de gente configuraba la élite de los Baymen que reclamaba múltiples lotes de caoba (Anderson, 2013, p. 12).

Estos mismos apellidos aparecen en un mapa de 1814 que prefigura un registro catastral (Hoffmann, 2014), sin que existan todavía formas sistemáticas de registro de la propiedad. Cuando existen, los "títulos de propiedad" no son más que acuerdos privados, a veces registrados frente a la autoridad local, que garantizan la validez de la transacción. Este sistema se parece al descrito en 1840 en el Petén guatemalteco, región vecina, por el viajero Morelet (citado por Torras, 2014), quien dice: "La posesión es el único título que los habitantes reconocen; el que desmonta un terreno es dueño de él todo el tiempo que quiere; si por casualidad se traba una disputa, la autoridad paternal del corregidor basta para calmarla" (p. 19). En Belice en esta época de colonización temprana no hay corregidor ni institución colonial reconocida, solo autoridades legitimadas por el colectivo.

En este sistema, la propiedad es de muy fácil acceso para algunos (hombres, colonos, blancos) y de total exclusión para la mayoría de entonces: los numerosos esclavos, las pocas mujeres, los mayas expulsados. El sistema está dibujado por 
y para la categoría que, es interesante notarlo, se autodeclara como Baymen: hombres de la bahía, ni británicos ni de otras nacionalidades, sino con una lealtad hacia el lugar donde viven: la bahía. Las limitaciones a la propiedad, en este caso a la posesión, dibujan claramente las fronteras de la comunidad política dominante en ciernes, misma que empieza a establecer las jerarquías de una sociedad colonial, racista, esclavista y extractivista.

En todo el siglo XVIII, el territorio no es colonia, sino asentamiento sin juridicidad clara ni internacionalmente reconocida. Los conflictos son numerosos entre el imperio español y los colonos de la bahía, respaldados por las fuerzas armadas inglesas. La victoria de estas últimas sobre los españoles en 1797 marca el principio de la autoridad de facto de la Corona británica sobre estas tierras, por momentos discreta a partir de Jamaica, y en otras ocasiones más imponente.

\section{La intervención británica y la primera institucionalización (1817)}

En 1817, por iniciativa del Superintendente Arthur, el gobierno británico asume autoridad sobre el conjunto del territorio de la Honduras británica. Se reconocen los derechos de posesión adquiridos antes mente sobre tierras ubicadas al norte, $y$ se declara toda la superficie restante, en la mitad sur del territorio, como Crown de esta fecha por los colonos, principal-

Lands (tierras de la Corona). A partir de este momento, se organiza el acceso a los terrenos de la Corona mediante un sistema de concesiones (Crown grants), que sienta las bases de una doble normatividad agraria. Por un lado, la propiedad privada (freehold), sometida al control monopolista de algunos cuantos terratenientes. Por otro, la posesión regulada por la Corona construye así un dispositivo político clientelar, que sobrevive hasta el siglo XXI. Sin embargo, estas disposiciones no suprimen del todo las anteriores. En la práctica, el sistema de Locations Laws se mantiene a la par del nuevo sistema de concesiones de la Corona en el que las transacciones se registran en un Deeds Registry (tabla 1). Los dos sistemas se desarrollan paralelamente y muchas veces se confrontan (Barnett, 1991, p. 57), lo que se traduce en el espacio en una configuración territorial dual que se mantiene prácticamente intacta hasta el siglo XXI (figura 1).

Tabla 1. Los primeros instrumentos jurídicos para regular la propiedad privada, siglos XVIII y principios del XIX

\begin{tabular}{|l|l|l|}
\hline \multicolumn{1}{|c|}{$\begin{array}{c}\text { Periodo } \\
\text { histórico }\end{array}$} & \multicolumn{2}{|c|}{$\begin{array}{c}\text { Instrumentos legales } \mathbf{y} \\
\text { administrativos de registro } \\
\text { de la propiedad }\end{array}$} \\
\hline $\begin{array}{l}\text { El asentamiento } \\
(1765-1787)\end{array}$ & Location System & \\
\hline $\begin{array}{l}\text { La institucio- } \\
\text { nalización, } \\
\text { Crown Grant } \\
\text { system (1817) }\end{array}$ & Location System & Deeds Registry \\
\hline
\end{tabular}

MODOS DE APROPIACIÓN TERRITORIAL EN BELICE: UNA GENEALOGÍA INSTITUCIONAL DE LA PROPIEDAD territarios 42-Especial 7 


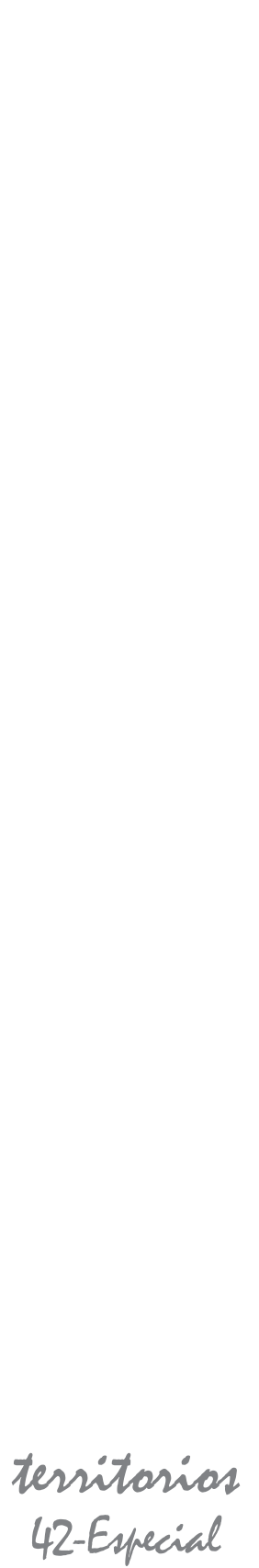

Figura 1. Configuración territorial de la propiedad en Belice

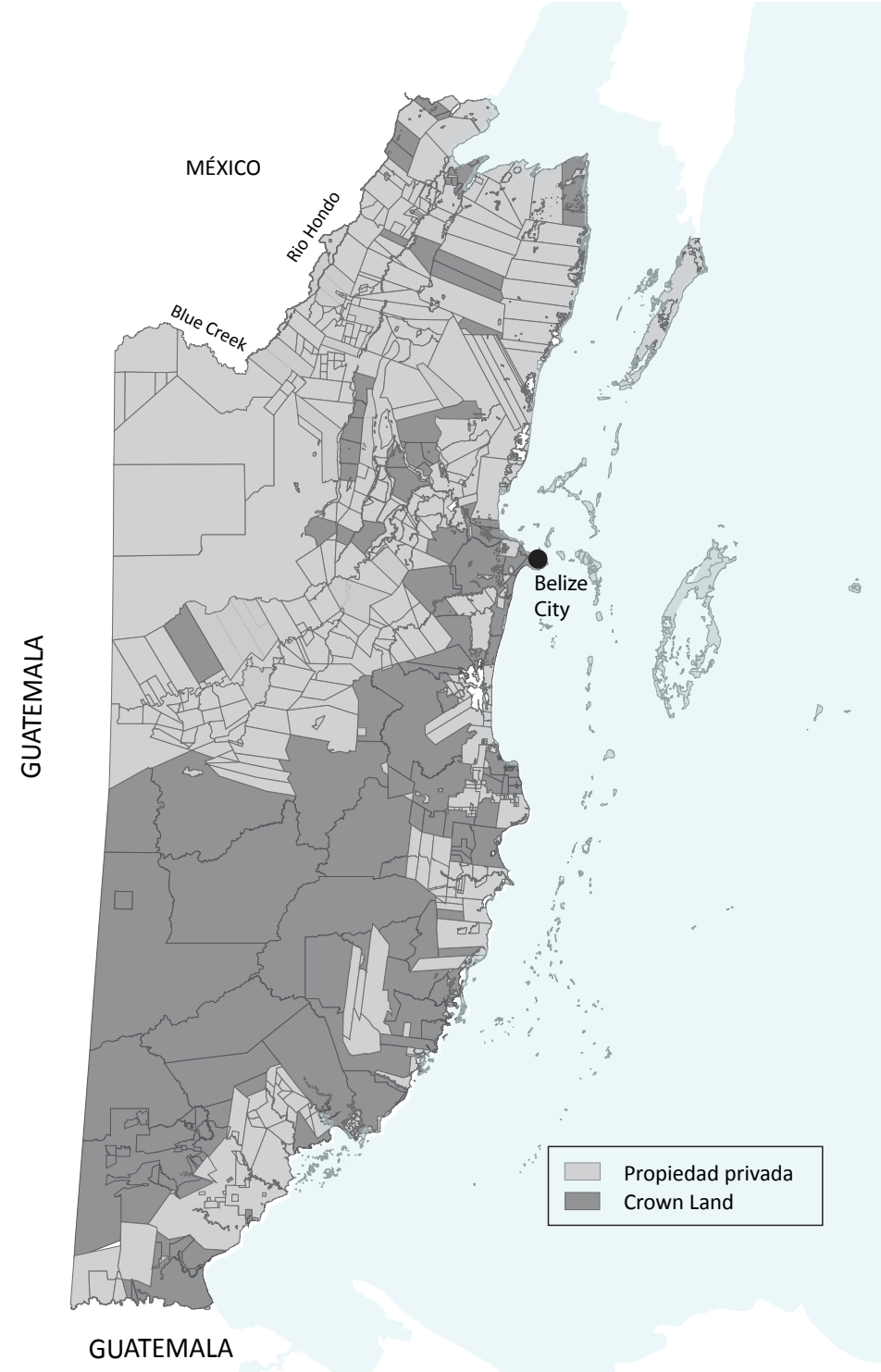


Cerca de medio siglo después de la declaración de 1817, la presencia de la autoridad británica no desemboca en un aparato administrativo-jurídico unificado y específico. Como lo afirma un reporte elaborado años más tarde: "De 1817 a 1872, las concesiones de tierras eran reguladas por simples directivas trasmitidas de vez en cuando al superintendente, en correos emitidos por la Secretaría del Interior (de gobierno) y no por disposiciones legislativas" (Bristowe \& Wright, 1889, p. 79).

Aunque sea en medio de una gran precariedad administrativa, las autoridades empezaron, sin embargo, a seguir ciertas normas del imperio británico para regular el acceso a la tierra. En 1831, se introduce el pago obligatorio de impuestos sobre tierras concesionadas por la Corona, lo que volvió su acceso muy difícil y hasta imposible para la mayoría de la población, la más pobre, constituida por negros libres y esclavos, mayas y mujeres. De esta forma se instituye, aunque no legalmente, la exclusión de la propiedad para estas capas subordinadas y se las mantiene dependientes del trabajo forestal (Bolland \& Shoman, 1977). Esta exclusión se extiende a los negros libres, aun después de la abolición de la esclavitud (18331838), ya que estos no pueden pagar los elevados precios exigidos por la Corona para acceder a las dotaciones. En otras palabras, de una manera similar a la de Estados Unidos (Barreyre \& Schor, 2009), la abolición de la esclavitud no significó el acceso a la tierra $-\mathrm{y}$ mucho menos a la propiedad - para la población negra que siguió dependiendo de los landowners y de la explotación maderera.

\section{La administración del territorio y la normalización colonial (1861)}

A partir del siglo XIX, el auge del mercado mundial de la caoba significó un cambio económico y tecnológico que tuvo un gran impacto sobre la organización territorial en Belice. A diferencia del palo de tinte, la caoba necesita una organización del trabajo muy compleja y demandante en tecnología, mano de obra e inversión. En aras de asegurar la inversión y el capital, la seguridad en la tenencia de la tierra se vuelve un asunto de interés tanto para los terratenientes, como para las autoridades. La regulación de la propiedad deviene un asunto de política pública. Además, con la llegada de los refugiados de Yucatán a partir de 1848 y a lo largo de la segunda mitad del siglo XIX, la población del territorio aumenta bruscamente, pasa de 8000 habitantes en 1841 a 25000 en 1861 y 38000 en 1901 (Hoffmann, 2014, p. 30).

La administración busca asegurar algún poder de regulación frente a los terratenientes que, hasta entonces, organizaban y controlaban casi solos la explotación de las tierras y la comercialización de los recursos extraídos del territorio. Pretende, además, introducir medidas de fiscalización y tributación, con lo que se acentúa el conflicto entre terratenientes, que, hay que recordarlo, sigue siendo precaria. territarios 42-Especial 


\section{territorias} 42-Especial
En 1854 -antes de ser declarada Colonia (en 1862) - las autoridades del territorio redactaron su primera constitución con una asamblea de 18 miembros electos y un poder importante del superintendente. Varias leyes y ordenanzas son emitidas en materia de regulación de la propiedad. Todas apuntan a segurizar la propiedad para los posesionarios anteriores (los grandes terratenientes), a la vez que reafirman la autoridad de la Corona para controlar el acceso y uso del territorio en su conjunto, y su capacidad de atribución en concesión de los Crown Lands que, desde 1817, forman la mitad sureña de la superficie total del territorio.

- 1855 Laws in Force Act: impone la aplicación de las leyes británicas en el territorio.

- 1858 Act for Quieting Titles to Land: asegura la vigencia de los antiguos títulos de propiedad.

- 1861 Honduras Land Titles Act: asegura la validez de las transacciones de propiedad aun en ausencia de títulos de propiedad originales.

- 1872 Crown Lands Ordinance ratifica el doble sistema de tenencia entre propiedad privada y Crown lands con una nueva versión en 1886.

Es en 1860, cuando la Corona introduce el sistema de tenencia y registro de la propiedad que existe, para entonces, en otras partes del imperio británico, conocido como el sistema Torrens. En este sistema, que fue concebido en Australia para registrar las propiedades europeas establecidas tras una colonización de tierras supuestamente deshabitadas y "sin dueño", la inscripción de la primera dotación en un gran "libro" administrado por el gobierno funge como título de propiedad. Las compraventas posteriores se inscribían en este mismo libro (el Land Title Registry, creado en Belice en 1859), que proporcionaba la prueba jurídica de la propiedad, con base en una multiplicidad de figuras legales: First Certificate of Title, Transfer Certificate of Title, Minister's Fiat, Lease, Deed of Assent, Deed of Assignment, Minister's Fiat Grant, Deed of Gift, Deed of Conveyance, Deed of Partition.

El sistema Torrens es una herramienta del gobierno colonial usada para retomar el control de la propiedad de la tierra frente a los landowners, quienes constituían el principal grupo de poder local y tendían a concentrar las riquezas y el poder. Al igual que los anteriores, sigue siendo, más que un dispositivo de control y ordenamiento territorial global, un instrumento parcial, destinado a organizar el reparto de la propiedad entre colonos, en un contexto de colonización de tierras supuestamente vacías.

No es un azar que precisamente en 1859 se cree la British Honduras Company, una compañía principalmente forestal, que llegó bajo el nombre de Belize Estate and Produce Company a controlar la mitad de las tierras privadas de la Colonia $(20 \% \mathrm{del}$ país) y constituyó un poder inmenso hasta 
bien entrado el siglo Xx. Ambos eventos - la introducción de un sistema de registro de la propiedad y la creación de una gran compañía forestal- son muestra de la nueva dinámica económica y productiva del territorio y de la necesidad de aclarar y asegurar los derechos de propiedad para atraer inversionistas. En efecto, aunque el mercado suele fluctuar en la segunda mitad del siglo XIX, la caoba sigue teniendo demanda y la administración se muestra benévola para los inversionistas (el gobierno colonial nunca logró aplicar una política fiscal operativa), de tal manera que el British Honduras se ha vuelto un espacio codiciado por los negociantes. Además, la población de la colonia aumentó bruscamente con la llegada de refugiados de Yucatán (México), quienes huyen de la guerra de castas (1848-1893) y se instalan en el norte; el sistema de registro y garantía de la propiedad se vuelve un asunto de primer plano.

En términos administrativos y jurídicos, el instrumento legal de registro del sistema Torrens (Land Titles Registry) debía sustituir al anterior (Deeds Registry); sin embargo, ese no es el caso, ambos coexisten sin que haya reglas claras para definir a cuál de los dos sistemas uno se tiene que atener cuando quiera vender o comprar un lote. Esto dependerá de la historia de la tenencia del lugar, del propietario anterior, del comprador, etc. Si se incluye el sistema de los Baymen (Location System) que no desapareció del todo, al terminar el siglo XIX son tres los mecanismos que permiten atestiguar la propiedad privada de un predio (tabla 2 ).

Tabla 2. Complejización de los instrumentos jurídicos de registro de la propiedad privada a finales del siglo XIX en relación con etapas previas

\begin{tabular}{|c|c|c|c|}
\hline Periodo histórico & \multicolumn{3}{|c|}{$\begin{array}{c}\text { Instrumentos legales y administrativos } \\
\text { de registro de la propiedad }\end{array}$} \\
\hline $\begin{array}{l}\text { El asentamiento } \\
(1765-1787)\end{array}$ & $\begin{array}{l}\text { Location } \\
\text { system }\end{array}$ & & \\
\hline $\begin{array}{l}\text { La institucionaliza- } \\
\text { ción, Crown Grant } \\
\text { System (1817) }\end{array}$ & $\begin{array}{l}\text { Location } \\
\text { system }\end{array}$ & Deeds Registry & \\
\hline $\begin{array}{l}\text { La normalización colonial, } \\
\text { el sistema Torrens (1861) }\end{array}$ & $\begin{array}{l}\text { Location } \\
\text { system }\end{array}$ & Deeds Registry & $\begin{array}{l}\text { Land Titles Registry } \\
\text { - privados- }-(1859)\end{array}$ \\
\hline
\end{tabular}

Fuente: Elaboración propia.

En el terreno continúa la dominación de las grandes propiedades. Algunos landowners las pierden cuando las ponen en garantía con prestamistas y negociantes que, debido a quiebres frecuentes, se quedan con los predios embargados. Mas estas trasmisiones no alteran la estructura global de la propiedad y se mantiene una fuerte concentración de la tierra en pocas manos. Por su parte, el gobierno conserva la capacidad de atribuir parcelas de Crown Lands con el sistema de location tickets.

A principios del siglo XX, el tema de la tenencia y la concentración de la tierra parece preocupar a las autoridades, que solicitan reportes sobre este tema. Varios informes tratan de la manera en que la estructura de la propiedad puede fomentar u obstaculizar el desarrollo del territorio, en particular el desarrollo agrícola. territarios 42-Especial 
4 "We are of the opinion that no difficulty in obtaining land, for agricultural purpose, exists. Most of the large landowners are willing and even desirous, of renting their lands on reasonable terms for this purpose" (Report on Agriculture Commission, 1917, p. 6, citado por Barnett, 1991, p. 88).

5 "It may be stated, generally, that over three-quarter of the productive land of the colony is privately owned. (...) The private ownership of land in such large amounts has engendered wasteful, extravagant, and careless practices" (Report on the Economic and Natural Features of British Honduras in Relation to Agriculture, with Proposals for Development, 1920, p. 1, citado por Barnett, 1991, p. 89).

\section{territorias 42-Especial}

En 1911, en respuesta a una encuesta llevada por la Corona en 14 de sus colonias y protectorados, el Acting Governor Wilfred Collet — en representación del gobierno colonial local en Belice-distinguió entre las tierras de propiedad privada $(51 \%$ del total) y las tierras atribuidas en lease, es decir renta o concesión (46\%). Menciona dos reservas "caribs" (garífunas), pero desconoce otro tipo de tenencia, la colectiva indígena que, contradictoriamente, por estos mismos años su propio gobierno intentó promover. Afirma tajantemente que toda la tierra disponible está bajo el control de la Corona y que ningún grupo nativo reivindica la propiedad (Harcourt, 1912). Otro informe, en 1917, se enfocó hacia los posibles futuros de la agricultura en el territorio, un tema estratégico dadas las penurias crónicas en alimentos. Sostuvo que el problema no provenía de la concentración de las tierras y que no había mayor problema en cuanto al acceso a las tierras de cultivo, ya que los grandes propietarios rentan porciones de sus tierras a precios accesibles. ${ }^{4}$ Un tercer informe, en 1920, sobre el mismo tema, presentó una opinión radicalmente opuesta. Señaló que las tres cuartas partes de la superficie productiva estaban en manos de la gran propiedad privada, y denunció sin equívoco el hecho de que tal predominio había generado prácticas de despilfarro y negligencia. ${ }^{5}$

El gobierno local no reaccionó a pesar de que la situación empeoró en el territorio. La pobreza extrema se generalizó y las movilizaciones se multiplicaron a principios de los años 30 en contra de los terratenientes, en particular, en contra de la compañía forestal Belize Estate and Produce Company. La huelga de 1934, liderada por Antonio Soberanis, fue el preludio del movimiento independentista que desembocó, en 1962, en la declaración del autogobierno. Mientras tanto el gobierno emitía dos leyes que, en teoría, podrían mejorar la situación de las mayorías: la primera (Land Acquisition Ordinance), en 1947, buscó abrir el mercado de tierras para promover, una vez más y sin éxito, su uso en la agricultura, y la segunda (Landlord and Tenant Ordinance), en 1953, pretendió regular las relaciones entre propietarios y arrendatarios de tierras, las cuales se volvieron más tensas en esos años.

Estas dos iniciativas no revertieron las relaciones de fuerza entre terratenientes - la mayoría de ellos empresarios forestales-, arrendatarios y administración local, siempre a favor de los primeros. Las cosas solo empezaron a cambiar cuando la caoba dejó de ser el oro verde y la única riqueza reconocida de la colonia, y la colonia misma dejó de ser una evidencia frente a las reivindicaciones independentistas.

\section{La modernización en los años de gobierno autónomo (1962)}

Al decretarse el gobierno autónomo en 1962, la propiedad privada continuó concentrada en pocas manos y se siguieron 
registrando transacciones bajo el sistema centenario del Land Titles Registry. Por parte del gobierno, el sistema de National Lands sustituyó al de Crown Lands, que continuó con la misma lógica de atribución de concesiones, en gran parte clientelar. El gobierno atribuía lotes de tierra en dotación (grant) o en concesión (lease) a particulares que podían, después de cierto plazo y bajo determinadas condiciones, transformar su dotación en propiedad (freehold property). El trámite era relativamente simple y podía ser barato: requería la recomendación del representante político local (area representative).

Sin embargo, contrario a lo que dejaría pensar el procedimiento legal, el sistema de transacción de tierras parece bloqueado en sus dos grandes áreas. En el dominio privado, las transacciones se regían por regulaciones extremadamente limitantes para los compradores y vendedores. Cada propietario debía aportar la prueba de su propiedad legítima, reconstruyendo la genealogía de todas las transacciones anteriores hasta remontar a la primera dotación, lo que podía llevar años. En las tierras de la Nación, por su parte, dominaba un clientelismo exacerbado asociado a una corrupción que desalentaba el registro y la legalización de las transacciones, y hasta las transacciones mismas. Es decir, la Colonia británica dejó en herencia un dispositivo agrario jurídico asfixiado.

La década de 1960 fue de grandes transformaciones políticas y económicas que influyeron sobre el sistema agrario de Belice. En el contexto global de descolonización, se pregonó el paradigma del desarrollo e intervención estatal; se agotó el modelo extractivista de la caoba y se fomentó el desarrollo agrícola, y se desarrollaron otros recursos económicos, principalmente alrededor del turismo. En estos contextos de cambios, el control del territorio se volvió prioridad y dio pie a ciertas innovaciones.

La administración independiente regulaba emitiendo varias leyes que pretendían introducir un sistema de fiscalización (impuesto predial), asegurar el derecho de los arrendatarios frente a los terratenientes y limitar el poder de los extranjeros sobre tierras de la Nación en construcción.

- Ley de 1962 sobre reforma agraria (Ordinance of 1962, on land reform, security of tenure)

- Ley de 1966 sobre impuesto predial (Ordinance of 1966 on land tax, rural land utilization).

- Ley de 1973 que limita derechos de extranjeros a comprar tierras (Aliens Landholding Ordinance).

Con la ambición de acabar con el desorden jurídico-territorial, se introdujo un nuevo instrumento de administración de la propiedad: el catastro. Con esto, Belice adoptó el mismo sistema que los demás países del Caribe anglófono (como también lo había hecho en su momento con la introducción del sistema Torrens), y la nueva política gozó del apoyo financiero territarios 42-Especial 
6 Traducción libre de la autora.

\section{territarias 42-Especial}

y técnico internacional. Se importó una tecnología novedosa y se previó una cartografía a gran escala vinculada a un registro de todas y cada una de las parcelas del país. A cada parcela estaría asociado un número único de registro que luego facilitaría el control de la propiedad y de las transacciones. Los títulos de propiedad se simplificarían con solo dos tipos de derechos: la propiedad plena (freebold) o la concesión (leasehold). Con el catastro ya no era la adjudicación inicial la que garantizaba la propiedad, sino el registro de la parcela en el catastro y su expediente correspondiente.

La introducción del catastro se acompaña de un esfuerzo legislativo para asentar la modernización agraria. Dos leyes emitidas en 1977 - la Registered Land Ordinance (RLO) y la Land Surveyors Ordinance (LSO) - promovieron la simplificación del sistema de registro de la propiedad con, entre otras medidas, la creación de las áreas prediales (registration areas) en las que el catastro era obligatorio. Algunos años más tarde, el gobierno buscó promover el uso productivo de las tierras con el Land Utilization Act (LUA) en 1981 y el Land Tax Act en 1983. Finalmente, en 1992 el National Lands Act (NLA) sustituyó al Crown Lands Act y organizó globalmente el uso y manejo de las tierras nacionales.

Sin embargo, la aplicación de estas reformas en el terreno se volvió problemática. La instalación del catastro fue costosa - en dinero, tiempo y competencias- y delicada. En sus inicios, el catastro se implementó con el apoyo de agencias y fondos externos, pero la modernización no se completó en los tiempos previstos y el proceso sigue inconcluso hasta hoy, lo que conduce a una nueva distinción en la administración de tierras.

En la mitad norte del país, donde predominan las tierras privadas, la modernización se lleva a cabo, existe el catastro y las tierras están "registradas en la máquina" (en el sistema de catastro). Son tierras declaradas en un registro de tierras: Declared land, Land Registry. En la otra mitad del país, principalmente en el sur donde predominan las tierras nacionales, la modernización catastral se detiene antes de completarse. Las tierras son no declaradas (Undeclared Land, en negativo) y siguen registradas en el anterior Land Titles Registry.

Podría pensarse que esta distinción es meramente técnica. Sin embargo, es también altamente política en la medida en que el catastro es más que un instrumento de la administración para manejar el territorio. Es un saber que instituye, jurídica y geográficamente hablando, la propiedad, que es a su vez garante de la ciudadanía. Lund (2013) remarca al respecto que "los reclamos por más ciudadanía son en parte arbitrados a través de los derechos de propiedad sobre la tierra y los reclamos a (gozar de) un lugar de vida". ${ }^{6}$ En este sentido, la producción de un catastro ocupa un lugar central en la construcción de un Estado, de su anclaje 
local y de su legitimidad (Colin, le Meur \& Léonard, 2010, p. 24). La incapacidad de implementarlo es una muestra de la falla del gobierno en hacer respetar uno de los derechos elementales vinculados a la ciudadanía: la propiedad.

Concretamente, hoy se sobreponen los instrumentos jurídicos elaborados desde las épocas anteriores. Ya no son tres, sino cuatro sistemas de registro de la propiedad que coexisten (tabla 3 ) y generan cierta confusión entre los usuarios. Esta confusión (algunos hablan de caos) es significativa del escaso dominio y control de la propiedad territorial por parte de la administración.

\section{Conclusión}

El saber jurídico-territorial en Belice es producto de la violencia de la modernidad occidental (la esclavitud, la colonización, el despojo) y de unas construcciones originales elaboradas en distintas épocas para conocer y apropiarse del territorio.

La presencia europea marcó el inicio de la mercantilización del saber sobre el espacio, con la inserción de los conocimientos territoriales en la lógica de la apropiación legalizada por derechos instituidos. Pero la apropiación jurídica del espacio no siguió un patrón unívoco. Las distintas modalidades que adquirió revelan los variados órdenes territoriales y las relaciones de poder que los sustentan.

Los sistemas de registro se atienen a concepciones y prácticas de la propiedad
Tabla 3. Confusión en los instrumentos jurídicos de registro de la propiedad privada hasta el siglo $\mathrm{XX}$

\begin{tabular}{|l|l|l|l|l|}
\hline \multicolumn{1}{|c|}{ Periodo histórico } & \multicolumn{3}{|c|}{$\begin{array}{l}\text { Instrumentos legales y administrativos } \\
\text { de registro de la propiedad }\end{array}$} \\
\hline $\begin{array}{l}\text { El asentamiento } \\
\text { (1765-1787) }\end{array}$ & $\begin{array}{l}\text { Location } \\
\text { system }\end{array}$ & & & \\
\hline $\begin{array}{l}\text { La institucionaliza- } \\
\text { ción, Crown Grant } \\
\text { system (1817) }\end{array}$ & $\begin{array}{l}\text { Location } \\
\text { system }\end{array}$ & $\begin{array}{l}\text { Deeds } \\
\text { Registry }\end{array}$ & Deeds \\
\hline $\begin{array}{l}\text { La normalización } \\
\text { colonial, el sistema } \\
\text { Torrens (1861) }\end{array}$ & $\begin{array}{l}\text { Location } \\
\text { system }\end{array}$ & $\begin{array}{l}\text { Registry Titles Registry, } \\
\text { creado en 1859 } \\
\text { (privados) }\end{array}$ & \\
\hline $\begin{array}{l}\text { La modernización, } \\
\text { el catastro (1977) }\end{array}$ & $\begin{array}{l}\text { Location } \\
\text { system }\end{array}$ & $\begin{array}{l}\text { Deeds } \\
\text { Registry }\end{array}$ & $\begin{array}{l}\text { Land Titles } \\
\text { Registry, en los } \\
\text { Undeclared land }\end{array}$ & $\begin{array}{l}\text { Land Registry, } \\
\text { en los Declared } \\
\text { land }\end{array}$ \\
\hline
\end{tabular}

Fuente: Elaboración propia.

que activan distintos registros de autoridad y legitimidad y definen los contornos de las comunidades políticas en presencia y, más globalmente, de la ciudadanía en los distintos momentos.

Los primeros mecanismos de apropiación remitían a prácticas individuales avaladas por un colectivo de habitantes. Por encima de una lógica de colonización, la explotación forestal estructuraba la ocupación del espacio (locations laws) y la apropiación apuntaba prioritariamente a excluir ciertos grupos del acceso a las riquezas territoriales (la madera). La comunidad política dominante era entonces idealmente conformada por colonos blancos, aun si en la realidad varios terratenientes forestales pudientes eran mestizos y mulatos.

Más tarde aparecieron modalidades de apropiación reguladas por un colectivo territorias 42-Especial 


\section{territorias} 42-Especial más extenso reconocido a la vez por los colonos y por el poder colonial, que se reservaba la autoridad de adjudicar ciertas tierras a ciertos precios. A través de los grants and leases, el gobierno local se constituyó en rector de una comunidad política local ampliada. El colectivo colonial - terratenientes, negociantes y administración- guardó control discrecional, muchas veces clientelar y corrupto, sobre la distribución de las tierras y, por ende, sobre las dinámicas sociales, económicas y políticas del territorio.

Finalmente, a partir de la segunda mitad del siglo XIX, las modalidades de apropiación (sistema Torrens, catastro) cambiaron y se refirieron a una autoridad y un espacio político de mayor envergadura, instituidos y regulados por instrumentos como las leyes, los reglamentos y las administraciones.

La evolución de los sistemas de registro de la propiedad ilustra los pasos de la construcción de la sociedad colonial, partiendo de una oposición "simple" entre colonos y esclavos hasta llegar a la social y económicamente compleja de hoy. Revela los procesos de exclusión (esclavos, mayas, negros, mujeres), así como los fenómenos de jerarquía y poder asentados en el control de la propiedad (la lógica de colonización con el sistema Torrens y del mercado liberal con el catastro). En este sentido, la edificación de un saber territorial especializado delimita los espacios de gobierno y las comunidades políticas que se disputan el control de las riquezas.
Las relaciones tejidas alrededor de las categorías jurídicas y sus jerarquías suelen ser movilizadas por actores poderosos y dominantes en ciertos momentos y espacios. En Belice este fue el caso con los colonos-terratenientes forestales antes del establecimiento de la Colonia en 1862, con la empresa inglesa Belize Estate and Produce Company durante casi un siglo, entre 1859 y 1950 (Hoffmann, 2019) o de la compañía Cramer, en el sur del país (Wainwright, 2003), hasta la Segunda Guerra Mundial. Estos actores territoriales, en sus contextos respectivos, dominaban ampliamente tanto el mercado de tierras, como el de trabajo y la escena política colonial.

Sin embargo, en otros espacios y momentos, no hubo tal monopolización de la propiedad ni existió una dominación tan extensa de un grupo reducido de actores sobre los recursos territorializados y la gente que depende de ellos. El modelo no está totalmente cerrado, deja intersticios y posibilidades de cambio en sus márgenes. Esto se vio en 1960, después de la declaración de autogobierno, cuando en el norte del país se implementó una redistribución de tierras a favor de los campesinos, que algunos calificaron de reforma agraria. La palabra puede parecer exagerada en la medida en que se trató de un reparto limitado y controlado de parcelas de caña de azúcar a los productores que ciertamente lucharon por ello, pero en un contexto en que el crecimiento del sector cañero respondía ante todo a los 
intereses de la industria azucarera y de la economía nacional. Es decir, esta reforma no propició un cambio profundo en las relaciones de poder regional o local entre propietarios de la tierra, del trabajo, de las finanzas y de los medios de transformación del producto.

Una situación muy diferente se vive desde finales del siglo $\mathrm{Xx}$, cuando amplios sectores de la población maya del distrito de Toledo iniciaron una lucha por controlar el acceso y manejo de sus tierras. Argumentan por un lado su legitimidad a gozar de derechos territoriales en lo que fueron sus territorios ancestrales, y por otro, la propiedad de hecho que mantienen en las áreas de reservas coloniales ahora calificadas de tierras comunales - communal lands, maya homeland - (Wainwright \& Bryan 2009). Con este doble registro de reivindicaciones, se abre un nuevo episodio de la historia de la propiedad en Belice. A la aparición de nuevas categorías de tenencia de propiedad, corresponden nuevos derechos, autoridades y legitimidades como lo atestigua la generalización de las nociones de pueblo autóctono, sujeto étnico, autoridad maya. El saber territorial evoluciona junto con la sociedad y los actores que se organizan, instituyen y emprenden luchas por su reconocimiento frente a sus vecinos y gobiernos.

\section{Referencias}

Anderson, J. (mayo, 2013). Mapping the politics of mahogany in Belize, 1786-1814.
San Ignacio, Belize: Association of Caribbean Historians. Ponencia presentada en la cuadrigésimo quinta conferencia anual de la Asociación Caribeña de Historiadores (ACH), ACH Ambergis Caye, Belice.

Antochiw, M., \& Breton, A. (1992). Catálogo cartográfico de Belice. Cartographic catalogue of Belize, 1511-1880. México: CEMCA.

Barnett, C. N. (1991). The political economy of land in Belize, 'Machete must fly'. (Tesis de doctorado, University of the West Indies, Mona, Jamaica).

Barreyre, N., \& Schor, P. (2009). De l'émancipation à la ségrégation: le Sud des Etats-Unis après la guerre de Sécession (1865-1896). Paris: PUF.

Bolland, N. (2004). Colonialism and resistance in Belize: Essays in historical sociology. Belice: Cubola Productions.

Bolland, N. O., \& Shoman, A. (1977). Land in Belize, 1765-1871. Kingston: University of the West Indies.

Bristowe, L., \& Wright, P. (1889). The handbook of British Honduras, 1888-1889. London: Blackwood.

Buttimer, A. (1969). Social space in interdisciplinary perspective. Geographical Review, 59, 417-26.

Colin, J.-P., le Meur, P.-Y., \& Léonard, E. (Eds.). (2010). Les politiques d'enregistrement des droits fonciers: $d u$ cadre légal aux pratiques locales. Paris: Karthala.

Dobson, N. (1973). A history of Belize. London: Longman Caribbean. territarios 42-Especial 
Frémont, A. (1976). La région, espace vécu. Paris: PUF.

Harcourt, L. (1912). Land in Crown colonies and protectorates and colonial office. Journal of the Society of Comparative Legislation, 13(1), 11-40.

Hoffmann, O. (2014). British Honduras: The invention of a colonial territory. Mapping and spatial knowledge in the 19th century. Belice: Cubola Production - IRD.

Hoffmann, O. (2018). Las configuraciones territoriales de movilidad, o el espacio como lenguaje político. En O. Hoffmann \& A. Morales (Coords.), El territorio como recurso: movilidad y apropiación del espacio en México y Centroamérica (pp. 23-40). San José Costa Rica: UNA-FLASO-IRD.

Hoffmann, O. (2019). The end of the empire forestry? Issues of land possession in Belize, 1930-1950. En D. Guignard \& I. Seri-Hersch (Eds.), Spatial appropriations in modern empires, 1820-1960-beyond dispossession (pp. 50-74). Newcastle upon Tyne: Cambridge Scholars Publishing.

Lefebvre, H. (1974). La production de l'espace. París: Anthropos.
Leslie, R. (2004). A bistory of Belize, a nation in the making. Belize: Cubola Productions.

Lund, C. (2013). Propriété et citoyenneté. Dynamiques de reconnaissance dans l'Afrique des villes. Politique Africaine, 132(4), 5-25.

Sikor, T., \& Lund, C. (2009). Access and property: A question of power and authority. Development and Change, 40(1), 1-22. https://www.doi.org/10.1111/ j.1467-7660.2009.01503.x

Torras, R. (2014). Los refugiados mayas yucatecos en la colonización de El Petén: Vicisitudes de una frontera. Boletín Americanista, 2(69), 15-32.

Toussaint, M. (1993). Belice: Una historia olvidada. México: Instituto Mora-CEMCA.

Wainwright, J. (2003). Decolonizing development: Colonialism, Mayanism, and agriculture in Belize. (Tesis de doctorado, University of Minnesota).

Wainwright, J., \& Bryan, J. (2009). Cartography, territory, property: Postcolonial reflections on indigenous counter-mapping in Nicaragua and Belize. Cultural Geographies, 16, 153-178. 